\title{
Strong Binding Site Molarity of MOFs and Its Effect on $\mathrm{CO}_{2}$
}

\section{Adsorption}

\author{
Yang Liu ${ }^{\text {a,b }}$, Jing Liu ${ }^{b}$, Y. S. Lin ${ }^{a, *}$ \\ ${ }^{a}$ School for Engineering of Matter, Transport and Energy, Arizona State University, Tempe, AZ \\ 85287-6006, USA \\ ${ }^{\mathrm{b}}$ State Key Laboratory of Coal Combustion, Huazhong University of Science and Technology, \\ Wuhan 430074, China
}

ABSTRACT: Metal organic frameworks (MOFs) with strong binding sites usually have remarkable $\mathrm{CO}_{2}$ adsorption capacity at ambient conditions. A new material parameter, the strong binding site molarity, defined as the number of the strong binding sites divided by the molecular weight of the unit cell of MOF, is introduced to understand $\mathrm{CO}_{2}$ adsorption on these MOFs. The $\mathrm{CO}_{2}$ adsorption capacity can be correlated to the strong binding site molarity in 1:1 ratio. The strong binding site coverage by $\mathrm{CO}_{2}$ molecules can also be correlated to the isosteric heat of $\mathrm{CO}_{2}$ adsorption at a given pressure. The strong binding site molarity is used to predict $\mathrm{CO}_{2}$ adsorption amount of several new types of MOFs to show its uses in selection or design of MOFs for $\mathrm{CO}_{2}$ capture.

KEYWORDS: MOFs; $\mathrm{CO}_{2}$ adsorption; Strong binding sites molarity; Site coverage

* Correspondence author: Y.S. Lin, email address: jerry.lin@ asu.edu, tel. 480-965-7769 
Metal organic frameworks (MOFs) are known for their extraordinarily high surface area, tunable pore size and adjustable internal surface properties, and have shown good potential for the utilization in $\mathrm{CO}_{2}$ capture [1]. Among all types of MOF materials, MOFs with unsaturated metal sites (or called open metal sites) are reported to exhibit remarkable $\mathrm{CO}_{2}$ adsorption capacity at low pressures [2-4]. The unsaturated metal sites are usually obtained following desolvation of the MOF material, where one of the solvent molecules in the coordination sphere of the metal center is removed in vacuo at elevated temperatures [1]. Thus the unsaturated metal sites serve as charge-dense binding sites for $\mathrm{CO}_{2}$, which is adsorbed more strongly on these sites owning to its greater quadrupole moment and polarizability compared with $\mathrm{N}_{2}$ [1]. Neutron diffraction measurements and density functional theory (DFT) calculations have confirmed that the unsaturated metal sites are primary binding sites for $\mathrm{CO}_{2}[5,6]$. Recent studies have also shown that amine modification on the unsaturated metal sites of MOFs can enhance the $\mathrm{CO}_{2}$ adsorption capacity for the application of $\mathrm{CO}_{2}$ capture from air or from stationary combustion sources [7-9]. A hydrogen-bonded complex involving two carbamic acid moieties was formed which results in 2:2 amine: $\mathrm{CO}_{2}$ stoichiometry with higher capacity and weaker binding energy than the 2:1 stoichiometry observed in most amine-functionalized adsorbents [10]. Overall, both unsaturated metal cations or alklyamines inside the pores of MOFs can be considered as strong binding sites for $\mathrm{CO}_{2}$ adsorption, resulting in high $\mathrm{CO}_{2}$ adsorption capacity at low pressure range $[1,8,9]$.

Many studies have investigated the nature of binding site and its effect on $\mathrm{CO}_{2}$ adsorption at low pressure for a specific MOF [5-12]. However, there lacks effort to compare $\mathrm{CO}_{2}$ adsorption on various MOF with strong binding sites. We analyzed $\mathrm{CO}_{2}$ adsorption on various MOFs with strong binding sites and found that the $\mathrm{CO}_{2}$ adsorption data can be correlated by one 
parameter related to the amount of the strong binding sites per unit mass of MOF. Here we report analysis of the $\mathrm{CO}_{2}$ adsorption on various MOFs by this parameter.

We define binding site molarity $\mathrm{SM}(\mathrm{mmol} / \mathrm{g})$ for a MOF as:

$$
\mathrm{SM}=1000 \cdot \mathrm{N}_{\text {site }} / \mathrm{W}_{\text {u.c. }}
$$

where $\mathrm{N}_{\text {site }}$ and $\mathrm{W}_{\text {u.c. }}(\mathrm{g} / \mathrm{mol})$ are number of strong binding site and molecular weight per unit cell of MOF. $\mathrm{N}_{\text {site }}$ can be obtained by calculating the number of unsaturated metal cations or incorporated amines. For example, there are 18 unsaturated $\mathrm{Mg}$ cations in every unit cell of $\mathrm{Mg} / \mathrm{DOBDC}$. These 18 cations are considered as strong binding sites because all of them can strongly interact with $\mathrm{CO}_{2}$ molecules. Thus $\mathrm{N}_{\text {site }}$ equals 18 for $\mathrm{Mg} / \mathrm{DOBDC}$ materials. The binding site molality of reported MOFs with extremely strong binding sites is summarized in Table 1 . One can see that the value of binding site molality varies considerably among different MOFs because of the variation of molecular weight and the number of strong binding sites in MOFs. For example, though the number of strong binding sites of M/DOBDC $(\mathrm{M}=\mathrm{Mg}, \mathrm{Co}, \mathrm{Ni}$ and $\mathrm{Zn}$ ) series is same, their molecular weight differ from each other due to different types of metals being used in these materials, resulting in very different values for the binding site molarity for these materials.

Fig. 1 plots $\mathrm{CO}_{2}$ adsorption amount at $298 \mathrm{~K}$ and 1 bar versus corresponding binding site molarity for MOFs reported in the literature. It is remarkable to see that the $\mathrm{CO}_{2}$ adsorption amount is determined by the binding site molarity in 1 to 1 ratio. This suggests that $\mathrm{CO}_{2}$ adsorbed in a MOF would not occupy any other binding site unless the strong binding sites are fully occupied. The results show that every strong binding site inside the framework of these materials is occupied by one $\mathrm{CO}_{2}$ molecule under such a condition due to the strong interaction forces between the strong binding sites and $\mathrm{CO}_{2}$ molecules [5, 12]. For example, the binding 
energy between $\mathrm{CO}_{2}$ and $\mathrm{Mg}^{2+}$ cations of $\mathrm{Mg} / \mathrm{DOBDC}$ is calculated to be over $40 \mathrm{~kJ} / \mathrm{mol}$ [6]. Such strong binding strength will result in fast occupation of $\mathrm{Mg}^{2+}$ cations by $\mathrm{CO}_{2}$ molecules at low pressure, which is evidenced by the sharp increase of $\mathrm{CO}_{2}$ adsorption isotherm with increasing pressure in the low pressure range and at ambient temperature [13]. At room temperature, $\mathrm{CO}_{2}$ adsorption reaches saturation for all these MOFs with strong binding sites with $\mathrm{CO}_{2}$ pressure approaching 1 atm because they have similar high binding strength between different strong binding sites and $\mathrm{CO}_{2}$ molecules [6]. It should be noted that the $\mathrm{CO}_{2}$ binding strength at secondary binding sites, mainly organic linkers, are usually quite weak $[5,21,22]$ and thus the $\mathrm{CO}_{2}$ adsorption amount at these sites at $298 \mathrm{~K}$ and 1 bar is too small to be considered. Deviations are observed for several materials, as marked in Fig. 1, which is simply because of the limitation of surface area or pore volume. For instance, the bio-MOFs series have same number of strong binding sites, but their surface area are $1148 \mathrm{~m}^{2} / \mathrm{g}, 1008 \mathrm{~m}^{2} / \mathrm{g}, 412 \mathrm{~m}^{2} / \mathrm{g}$ and 17 $\mathrm{m}^{2} / \mathrm{g}$ for bio-MOF-11, 12, 13 and 14 respectively [18]. In the cases of bio-MOF-11 and 12, their surface area is large enough to accommodate sufficient $\mathrm{CO}_{2}$ molecules and thus their experimental adsorption data agree very well with the binding site molarity. In contrast, the surface area of bio-MOF-13 and 14 is too low, which means there is no enough space for $\mathrm{CO}_{2}$ molecules to occupy every strong binding sites. Thus reasonable surface area or pore volume is also an important consideration besides the binding site molarity.

Isosteric heat for $\mathrm{CO}_{2}$ adsorption on various MOFs at different adsorption amount is plotted in Fig. 2.a versus site coverage defined as:

$$
\theta_{\mathrm{A}}=\frac{\mathrm{m}_{\mathrm{ad}}}{\mathrm{SM}}
$$

where $\mathrm{m}_{\mathrm{ad}}(\mathrm{mmol} / \mathrm{g})$ is the adsorption amount of $\mathrm{CO}_{2}$ at a given pressure. One can see that at a given pressure value of $\theta_{\mathrm{A}}$ gradually increases with the increasing of isosteric heat, in the 
sequence $\mathrm{Zn} / \mathrm{DOBDC}<\mathrm{Co} / \mathrm{DOBDC}<\mathrm{Ni} / \mathrm{DOBDC}<\mathrm{Mg} / \mathrm{DOBDC}<\mathrm{Mg} / \mathrm{DOBPDC}<$ mmen$\mathrm{Mg} / \mathrm{DOBPDC}<$ en-Mg/DOBPDC. However, such a relationship does not exist when using isosteric heat versus $\mathrm{CO}_{2}$ adsorption amount, as shown in Fig. 2.b. Although the $\mathrm{CO}_{2}$ adsorption capacity of $\mathrm{Mg} / \mathrm{DOBDC}$ and $\mathrm{Mg} / \mathrm{DOBPDC}$ differ from each other significantly $[2,8]$, the site coverage by $\mathrm{CO}_{2}$ of these two materials are almost same at $1 \mathrm{kPa}$, which indicates the $\mathrm{Mg}^{2+}$ centers in these two materials have similar binding strength to $\mathrm{CO}_{2}$. Considering that these two materials have a similar structure but different size linkers, one can conclude that the higher $\mathrm{CO}_{2}$ adsorption capacity of $\mathrm{Mg} / \mathrm{DOBDC}$ comparing to $\mathrm{Mg} / \mathrm{DOBPDC}$ is due to its lower framework weight. However, the difference between these two values becomes larger as pressure increasing, as shown in Fig. 2. This may be due to the different adsorption potential generated by different size of pores of these two materials.

Since Fig. 1 shows that the $\mathrm{CO}_{2}$ adsorption amount is determined by the binding site molarity, we can use the binding site molarity to predict the $\mathrm{CO}_{2}$ adsorption capacity of MOFs with strong binding sites at ambient conditions. Table 2 shows that the molality of strong binding site in IRMOF-74 series materials. The $\mathrm{CO}_{2}$ adsorption capacity of these materials at ambient conditions, most of which haven't been reported by far, were estimated based on the values of binding site molality, as shown in Fig. 3. One can see that the $\mathrm{CO}_{2}$ adsorption capacity of IRMOF-74s series materials significantly decreases with increasing size of organic linkers. This is due to the limit of the number of strong binding site as well as the increase of molecular weight per unit cell of these MOFs, as shown in Table 2. After adding ethylenediamine (en) and $N, N^{\prime}$-dimethylethylenediamine (mmen) into the pores of IRMOF-74s, the $\mathrm{CO}_{2}$ adsorption capacity of these materials is significantly reduced comparing to the original materials but some of them are still among the best performance materials in the area of low pressure $\mathrm{CO}_{2}$ 
adsorption. The decrease can be attributed to the fact that the number of strong binding site per unit cell has not been changed but the molecular weight per unit cell has been significantly increased by adding en and mmen groups, as shown in Table 2 .

The $\mathrm{CO}_{2}$ adsorption capacity of tri(2-aminoethyl) or bis(3-amino-propyl) amine functionalized IRMOF-74s are estimated to be dramatically improved comparing to the original materials, as shown in Fig. 3. The enhancement in the $\mathrm{CO}_{2}$ adsorption capacity is due to the fact that the number of strong binding site per unit cell is doubled after functionalization even if the molecular weight is increased (see Table 2). It should be noted that attaching amine groups on unsaturated open metal sites of MOFs may not only increase $\mathrm{CO}_{2}$ adsorption capacity, but also reduce the effect of water vapor on $\mathrm{CO}_{2}$ capture in flue gas. McDonald et al. [20] found that the water vapor adsorption was significantly reduced in mmen-Mg/DOBDC. Here, we predict that a higher $\mathrm{CO}_{2}$ adsorption capacity would be obtained by attaching amine groups on IRMOF-74-III material comparing to mmen-Mg/DOBPDC, meanwhile, retaining the similar working capacity under water presence.

In conclusion, the $\mathrm{CO}_{2}$ adsorption amount of MOFs with strong binding site at ambient conditions is determined by the binding site molarity (SM) in 1 to 1 ratio. Meanwhile, a good correlation between the value of strong binding site coverage and isosteric heat is found. Our results show that the SM is a good parameter for estimating the $\mathrm{CO}_{2}$ adsorption capacity of MOFs, and the binding site coverage obtained using SM is useful to estimate the binding strength between $\mathrm{CO}_{2}$ and MOFs. Further work will be performed to extend the SM parameter for $\mathrm{CO}_{2}$ adsorption on zeolites which have countable number of cations. We are also interested in verifying this parameter using the adsorption data of different gases in MOFs with strong binding sites in the future. 


\section{口 AUTHOR INFORMATION}

\section{Corresponding author}

*E-mail address: jerry.lin@asu.edu

\section{Notes}

The authors declare no competing financial interest.

\section{口 ACKNOWLEDGMENTS}

The work was supported by the National Science Foundation (CBET-1160084), Natural

Science Foundation of Hubei Province and Foundation of State Key Laboratory of Coal Combustion (FSKLCCB1502).

\section{REFERENCES}

[1] K. Sumida, D.L. Rogow, J.A. Mason, T.M. McDonald, E.D. Bloch, Z.R. Herm, T.H. Bae, J.R. Long, Chem. Rev. 112 (2012) 724-781.

[2] S.R. Caskey, A.G. Wong-Foy, A.J. Matzger, J. Am. Chem. Soc. 130 (2008) 10870-10871.

[3] R. Banerjee, A. Phan, B. Wang, C. Knobler, H. Furukawa, M. O'Keeffe, O.M. Yaghi, Science 319 (2008) 939-943;

[4] A.O. Yazaydin, R.Q. Snurr, T.H. Park, K. Koh, J. Liu, M.D. LeVan, A.I. Benin, P. Jakubczak, M. Lanuza, D.B. Galloway, J.J. Low, R.R. Willis, J. Am. Chem. Soc. 131 (51) (2009) 1819818199.

[5] W.L. Queen, C.M. Brown, D.K. Britt, P. Zajdel, M.R. Hudson, O.M. Yaghi, J. Phys. Chem. C 115 (50) (2011) 24915-24919. 
[6] M.K. Rana, H.S. Koh, J. Hwang, D.J. Siegel, J. Phys. Chem. C 116 (2012) 16957-16968.

[7] S. Choi, T. Watanabe, T.H. Bae, D.S. Sholl, C.W. Jones, J. Phys. Chem. Lett. 3 (9) (2012) 1136-1141.

[8] T.M. McDonald, W.R. Lee, J.A. Mason, B.M. Wiers, C.S. Hong, J.R. Long, J. Am. Chem. Soc. 134 (16) (2012) 7056-7065;

[9] W.R. Lee, S.Y. Hwang, D.W. Ryu, K.S. Lim, S.S. Han, D. Moon, J. Choi, C.S. Hong, Energ. Environ. Sci. 7 (2) (2014) 744-751.

[10] N. Planas, A.L. Dzubak, R. Poloni, L.C. Lin, A. McManus, T.M. McDonald, J.B. Neaton, J.R. Long, B. Smit, L. Gagliardi, J. Am. Chem. Soc. 135 (20) (2013) 7402-7405.

[11] L. Chen, C.A. Morrison, T. Düren, J. Phys. Chem. C 116 (35) (2012) 18899-18909.

[12] H. Wu, J.M. Simmons, G. Srinivas, W. Zhou, T. Yildirim, J. Phys. Chem. Lett. 1 (13) (2010) 1946-1951;

[13] J.A. Mason, K. Sumida, Z.R. Herm, R. Krishna, J.R. Long, Energ. Environ. Sci. 4 (8) (2011) 3030-3040.

[14] H.Y. Cho, D.A. Yang, J. Kim, S.Y. Jeong, W.S. Ahn, Catal. Today 185 (1) (2012) 35-40.

[15] P.D.C. Dietzel, R.E. Johnsen, H. Fjellvåg, S. Bordiga, E. Groppo, S. Chavan, R. Blom, Chem. commun. (2008) 5125-5127.

[16] A.O. Yazaydin, A.I. Benin, S.A. Faheem, P. Jakubczak, J.J. Low, R.R. Willis, R.Q. Snurr, Chem. Mat. 21 (8) (2009) 1425-1430.

[17] J. An, S.J. Geib, N.L. Rosi, J. Am. Chem. Soc. 132 (1) (2010) 38-39.

[18] T. Li, D. L. Chen, J. E. Sullivan, M. T. Kozlowski, J. K. Johnson, N. L. Rosi, Chem. Sci. 4 (2013) $1746-1755$.

[19] A.R. Millward, O.M. Yaghi, J. Am. Chem. Soc. 127 (51) (2005) 17998-17999. 
[20] T. M. McDonald, J. A. Mason, X. Kong, E. D. Bloch, D. Gygi, A. Dani, V. Crocella, F. Giordanino, S. O. Odoh, W. S. Drisdell, B. Vlaisavljevich, A. L. Dzubak, Roberta Poloni, S. K. Schnell, N. Planas, K. Lee, T. Pascal, L. F. Wan, D. Prendergast, J. B. Neaton, B. Smit, J. B. Kortright, L. Gagliardi, S. Bordiga, J. A. Reimer, J. R. Long, Nature 519 (2015) 303-308

[21] Y. Liu, J. Liu, M. Chang, C.G. Zheng, Fuel 95 (2012) 521-527.

[22] Y. Liu, J. Liu, M. Chang, C.G. Zheng, J. Phys. Chem. C 116 (2012) 16985-16991. 
Table 1. Molecular weight $\left(\mathrm{W}_{\text {u.c. }}\right)$ and number of strong binding sites $\left(\mathrm{N}_{\text {site }}\right)$ per unit cell as well as binding site molality $\left(\mathrm{N}_{\text {site }} / \mathrm{W}_{\text {u.c. }}\right)$ of reported MOFs with extremely strong binding sites.

\begin{tabular}{|c|c|c|c|}
\hline material & $\mathrm{W}_{\text {u.c. }}(\mathrm{g} / \mathrm{mol})$ & $\mathrm{N}_{\text {site }}$ & $\mathrm{N}_{\text {site }} / \mathrm{W}_{\text {u.c. }}(\mathrm{mmol} / \mathrm{g})$ \\
\hline $\mathrm{Mg} / \mathrm{DOBDC}$ & 2178 & 18 & 8.26 \\
\hline $\mathrm{Co} / \mathrm{DOBDC}$ & 2807 & 18 & 6.41 \\
\hline Ni/DOBDC & 2803 & 18 & 6.42 \\
\hline $\mathrm{Zn} / \mathrm{DOBDC}$ & 2923 & 18 & 6.16 \\
\hline $\mathrm{Mg} / \mathrm{DOBPDC}$ & 3816 & 24 & 6.29 \\
\hline HKUST-1 & 9696 & 48 & 4.95 \\
\hline MOF-505 & 4086 & 18 & 4.41 \\
\hline bio-MOF-11 & 4032 & 16 & 3.97 \\
\hline bio-MOF-12 & 5424 & 16 & 2.95 \\
\hline bio-MOF-13 & 4720 & 16 & 3.39 \\
\hline bio-MOF-14 & 4832 & 16 & 3.31 \\
\hline en-Mg/DOBPDC & 5256 & 24 & 4.57 \\
\hline mmen-Mg/DOBPDC & 5928 & 24 & 4.05 \\
\hline mmen-Mn/DOBPDC & 6672 & 24 & 3.60 \\
\hline mmen-Fe/DOBPDC & 6796 & 24 & 3.58 \\
\hline mmen-Zn/DOBPDC & 6912 & 24 & 3.47 \\
\hline
\end{tabular}


Table 2. Molecular weight $\left(\mathrm{W}_{\text {u.c. }}\right)$ and number of strong binding sites $\left(\mathrm{N}_{\text {site }}\right)$ per unit cell as well as binding site molality $\left(\mathrm{N}_{\text {site }} / \mathrm{W}_{\text {u.c. }}\right)$ of unreported MOFs with extremely strong binding sites.

\begin{tabular}{|c|c|c|c|}
\hline material & $\mathrm{W}_{\text {u.c. }}(\mathrm{g} / \mathrm{mol})$ & $\mathrm{N}_{\text {site }}$ & $\mathrm{N}_{\text {site }} / \mathrm{W}_{\text {u.c. }}(\mathrm{mmol} / \mathrm{g})$ \\
\hline IRMOF-74-III & 3798 & 18 & 4.74 \\
\hline IRMOF-74-IV & 4734 & 18 & 3.80 \\
\hline IRMOF-74-V & 5670 & 18 & 3.17 \\
\hline IRMOF-74-VI & 6606 & 18 & 2.72 \\
\hline IRMOF-74-VII & 8802 & 18 & 2.04 \\
\hline en-IRMOF-74-III & 4878 & 18 & 3.69 \\
\hline en-IRMOF-74-IV & 5814 & 18 & 3.10 \\
\hline en-IRMOF-74-V & 6750 & 18 & 2.67 \\
\hline en-IRMOF-74-VI & 7686 & 18 & 2.34 \\
\hline en-IRMOF-74-VII & 9882 & 18 & 1.82 \\
\hline en-IRMOF-74-VIII & 11754 & 18 & 1.53 \\
\hline en-IRMOF-74-IX & 14886 & 18 & 1.21 \\
\hline mmen-IRMOF-74-III & 5382 & 18 & 3.34 \\
\hline mmen-IRMOF-74-IV & 6318 & 18 & 2.85 \\
\hline mmen-IRMOF-74-V & 7254 & 18 & 2.48 \\
\hline mmen-IRMOF-74-VI & 8190 & 18 & 2.20 \\
\hline mmen-IRMOF-74-VII & 10386 & 18 & 1.73 \\
\hline mmen-IRMOF-74-VIII & 12258 & 18 & 1.47 \\
\hline mmen-IRMOF-74-IX & 15390 & 18 & 1.17 \\
\hline bis(3-amino-propyl)-IRMOF-74-III & 6156 & 36 & 5.85 \\
\hline
\end{tabular}




$\begin{array}{lccc}\text { bis(3-amino-propyl)-IRMOF-74-IV } & 7092 & 36 & 5.08 \\ \text { bis(3-amino-propyl)-IRMOF-74-V } & 8028 & 36 & 4.48 \\ \text { bis(3-amino-propyl)-IRMOF-74-VI } & 8964 & 36 & 4.02 \\ \text { bis(3-amino-propyl)-IRMOF-74-VII } & 11160 & 36 & 3.23 \\ \text { bis(3-amino-propyl)-IRMOF-74-VIII } & 13032 & 36 & 2.76 \\ \text { bis(3-amino-propyl)-IRMOF-74-IX } & 16164 & 36 & 2.23 \\ \text { tri(2-aminoethyl)-IRMOF-74-III } & 6426 & 36 & 5.60 \\ \text { tri(2-aminoethyl)-IRMOF-74-IV } & 7362 & 36 & 4.89 \\ \text { tri(2-aminoethyl)-IRMOF-74-V } & 8298 & 36 & 4.34 \\ \text { tri(2-aminoethyl)-IRMOF-74-VI } & 9234 & 36 & 3.90 \\ \text { tri(2-aminoethyl)-IRMOF-74-VII } & 11430 & 36 & 3.15 \\ \text { tri(2-aminoethyl)-IRMOF-74-VII } & 13302 & 36 & 2.71 \\ \text { tri(2-aminoethyl)-IRMOF-74-VII } & 16434 & 36 & 2.21\end{array}$




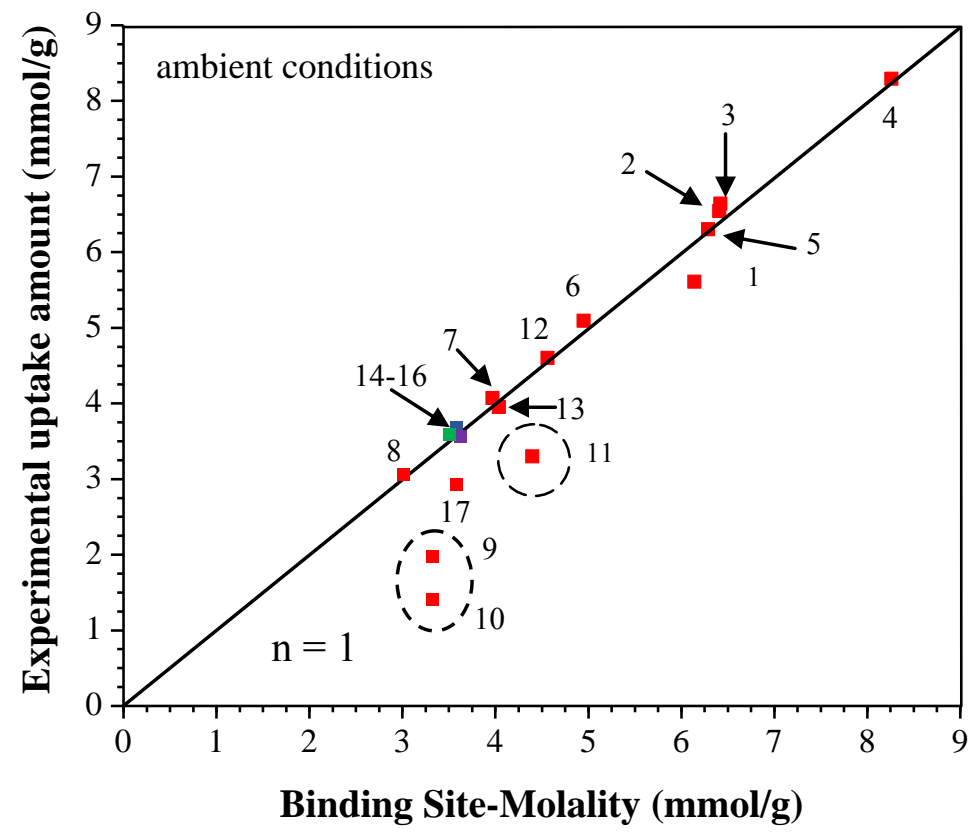

Fig. 1. Comparison of binding site molality and experimental $\mathrm{CO}_{2}$ uptake amount in MOFs with strong binding sites, including Zn/DOBDC [4], Co/DOBDC [14], Ni/DOBDC [15], Mg/DOBDC [13], Mg/DOBPDC [8], HKUST-1 [16], bio-MOF-11 [17], bio-MOF-12 [18], bio-MOF-13 [18], bio-MOF-14 [18], MOF-505 [19], en-Mg/DOBPDC [9], mmen-Mg/DOBPDC [8], mmenMn/DOBPDC (blue) [20], mmen-Fe/DOBPDC (purple) [20], mmen-Co/DOBPDC (green) [20] and mmen-Zn/DOBPDC [20] which are numbered from 1-17 respectively in the figure. The experimental data are obtained at $298 \mathrm{~K}$ and 1 bar. 

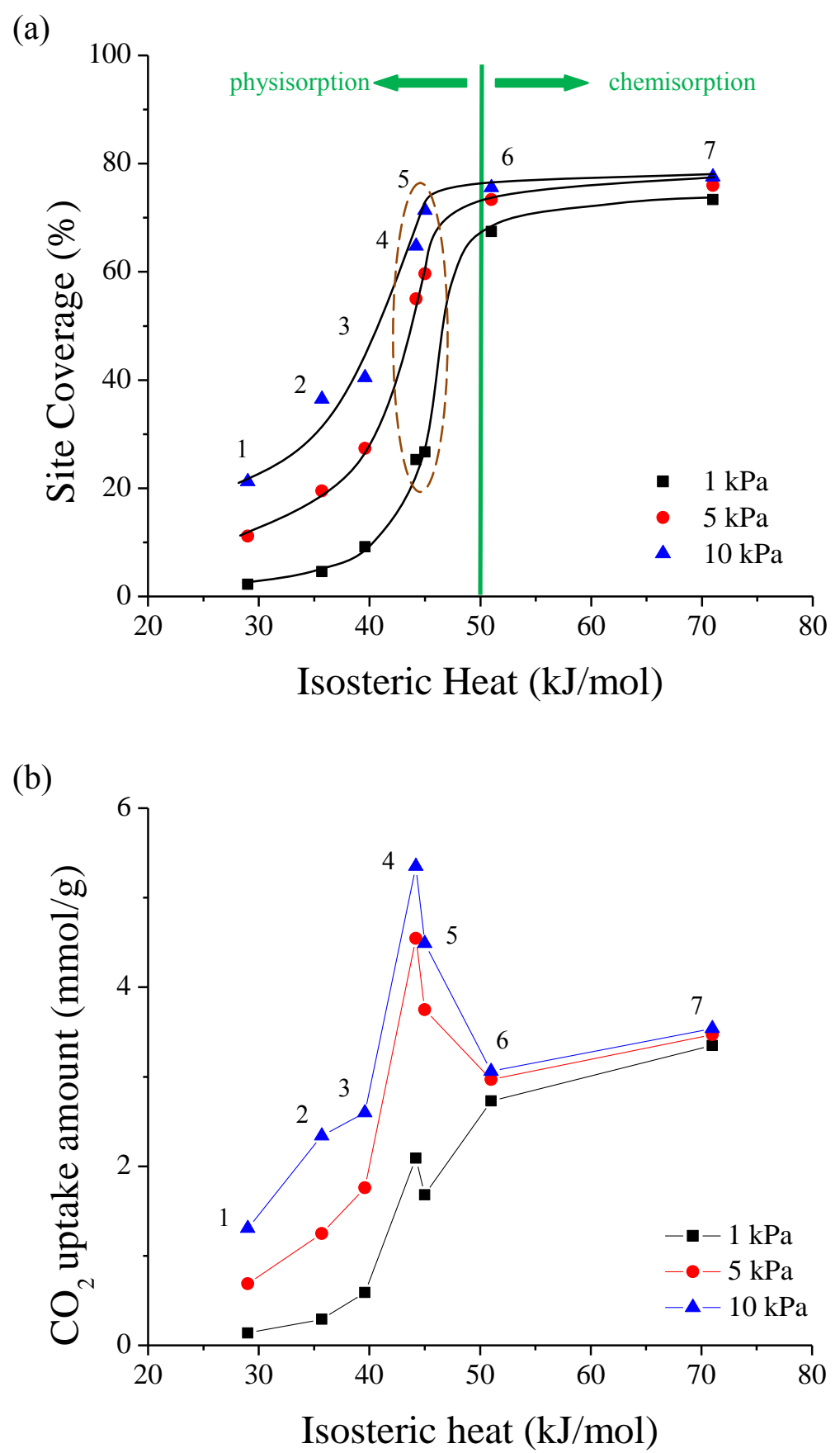

Fig. 2. The relationship between isosteric heat of $\mathrm{CO}_{2}$ adsorption on MOFs with strong binding sites and (a) site coverage or (b) $\mathrm{CO}_{2}$ uptake amount at 1, 5 and $10 \mathrm{kPa}, 298 \mathrm{~K}$. The numbers from 1-6 in the figures mean $\mathrm{Zn/DOBDC} \mathrm{[4],} \mathrm{Co/DOBDC} \mathrm{[14],} \mathrm{Ni/DOBDC} \mathrm{[15],} \mathrm{Mg/DOBDC}$ [13], Mg/DOBPDC [8], mmen-Mg/DOBPDC [8] and en-Mg/DOBPDC [9] respectively. 


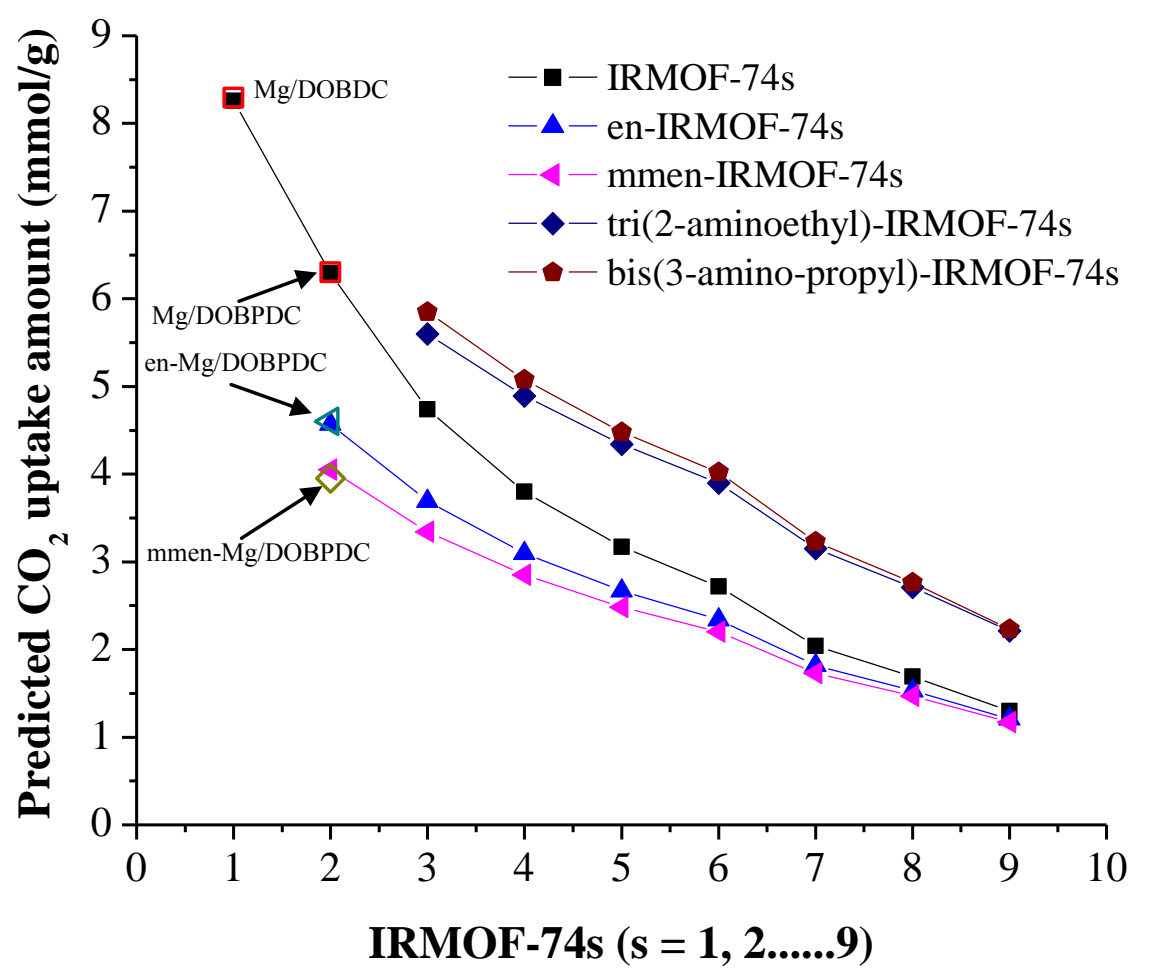

Fig. 3. Predicted $\mathrm{CO}_{2}$ adsorption amount in IRMOF-74s as well as their amine modified forms at ambient conditions. The experimental data of IRMOF-74-I (Mg/DOBDC) [13], IRMOF-74-II (Mg/DOBPDC) [8], en-IRMOF-74-II (en-Mg/DOBPDC) [9] and mmen-IRMOF-74-II (mmen$\mathrm{Mg} / \mathrm{DOBPDC}$ ) [9] are also shown in open symbol. 
Graphic Abstract

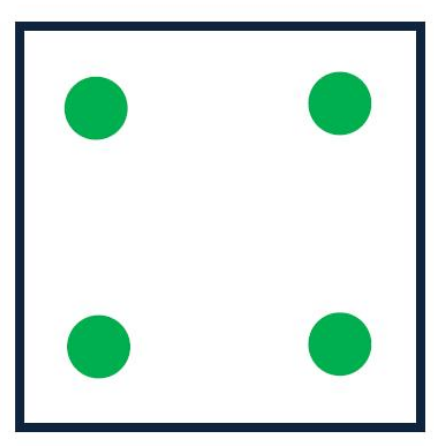

$\mathrm{CO}_{2}$ adsorption capacity depends on positions
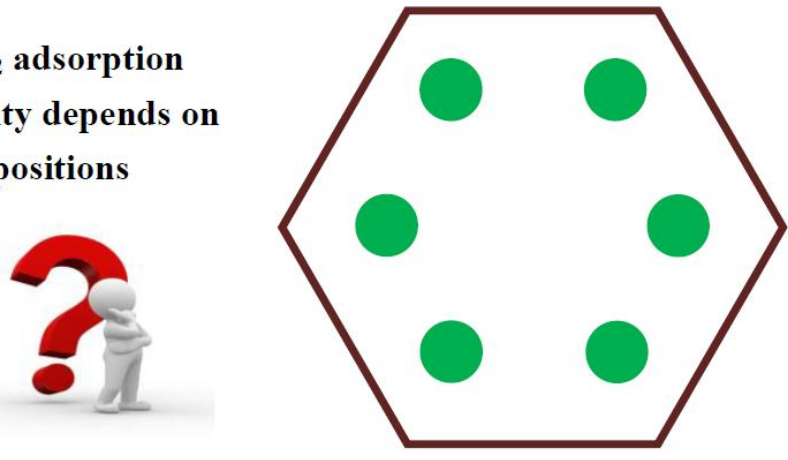